\title{
Managing Interpersonal Conflicts at Work by Line Managers
}

Research Article

Jennifer Lawless and Aurora Trif*

DCU Business School,

Dublin City University, Ireland

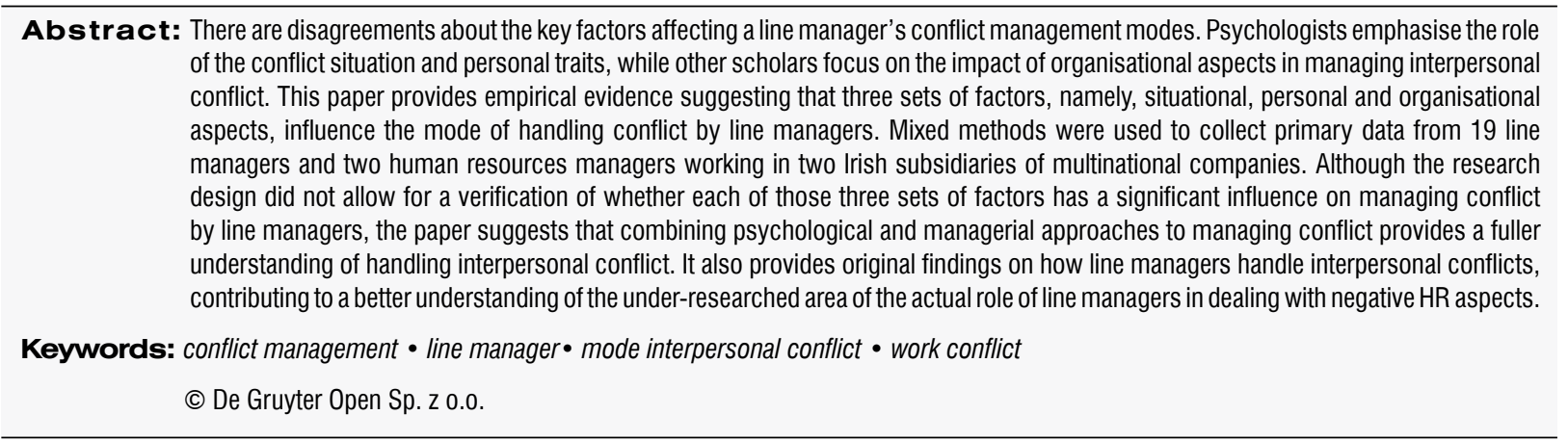

\section{Introduction}

Interpersonal work conflict refers to a disagreement among individuals. It is often associated with negative emotions due to a perceived divergence of views, goals, interests and proposed courses of action (Darling and Walker, 2001). Conflict management is based on the principle that it is impossible (and not always desirable) to eliminate conflict and not all conflicts can be resolved, but learning how to manage work conflicts is beneficial for employees and the organisation (Dreu and Weingart, 2003; Teague and Roche, 2012). Traditionally, managers considered that suppressing conflict and keeping peace at all costs was the best way to manage conflict. However, the recent view is that conflicts may be a warning sign for a more serious problem that needs to be resolved (Darling and Walker, 2001). Although not all problems and conflicts can be resolved, managing conflicts can 'minimize the dysfunctions of conflict and enhancing the constructive functions of conflict in order to enhance learning and effectiveness in an organization' (Rahim, 2002: 208).

While recent studies indicate that line managers handle workplace conflicts in many organisations, there is little theoretical and empirical research on how they actually perform such unpopular HR roles (Hunter and Renwick, 2009; Björkman et al., 2011). Moreover, there are disagreements about the key factors influencing line managers' conflict management modes; psychologists emphasise the role of the conflict situation (Rahim, 2002, Thomas et al., 2008) and personal traits (Antonioni, 1998), while other scholars focus solely on the impact of the organisational aspects of managing interpersonal conflict (Teague and Roche, 2012). The contribution of this paper lies in investigating whether situational, personal and/or organisational aspects influence line managers' conflict management modes.

\section{Literature review}

A workplace conflict refers to 'a process in which one party perceives that its interests are being opposed or negatively affected by another party' (Wall and Callister, 1995: 517). The collective aspects of workplace conflict have

\section{*E-mail: aurora.trif@dcu.ie}

(๕) BY-NC-ND (c) 2016 Jennifer Lawless and Aurora Trif, published by De Gruyter Open. 
been widely investigated by industrial relations scholars. They generally consider that management and employees have different interests and, therefore, conflict is inevitable and needs to be managed through mechanisms such as collective bargaining or labour courts (Teague and Roche, 2012). However, there is rather limited research on individual conflict at work from a management perspective (Hunter and Renwick, 2009). This might be linked to the unitarist, managerial perspective, which considers that managers and employees work as a team and, therefore, individual conflict is very unlikely to occur. Nevertheless, empirical studies indicate that an interpersonal conflict is the most common type of workplace conflict (Dana, 2001).

As most jobs require interactions with people, an interpersonal conflict at work is considered inevitable (Darling and Walker, 2001; Chung-Yan and Moeller, 2010). Although a work conflict can foster innovation and mutual understanding, it has generally negative consequences if it is ignored. An interpersonal conflict is associated with organisational outcomes such as increased absenteeism and decreased levels of performance (De Dreu and Weingart, 2003). It is also associated with depression, anxiety, frustration and exhaustion. Line managers can reduce these negative effects by managing interpersonal conflicts (Rahim, 2002).

Conflict-handling modes illustrate 'the different strategies that people may use in dealing with others in potentially adversarial social or business situations' (Kleinman et al., 2003: 62). Most research on conflict-handling modes is derived from Blake and Mutton's (1964) seminal work, which categorised these modes considering the level of concern for people and production (Holt and DeVore, 2005; Daly et al., 2010). Based on this model, the most widely used re-conceptualisations of conflict management modes are those developed by Thomas (1976) and Rahim (1983). Rahim (1983) identified five modes of handling interpersonal conflicts based on the level of concern for self and others: integrating, obliging, dominating, avoiding and compromising modes. Thomas (1976) also developed a two-dimensional framework of conflict-handling modes, which distinguished five conflict-handling modes: collaborating, accommodating, competing, avoiding and compromising, depending on the level of cooperativeness and assertiveness of the parties involved in the conflict. For instance, Thomas et al. (2008) argue that assertive people attempt to satisfy their own concerns, while cooperative people attempt to satisfy the concerns of others. Hence, there is a large degree of overlap between the conflict-handling modes identified by Thomas and Rahim (Holt and DeVore, 2005; Daly et al., 2010: 284), as indicated in Figure 1.

Figure 1. Two-Dimensional Model of Conflict Handling Modes

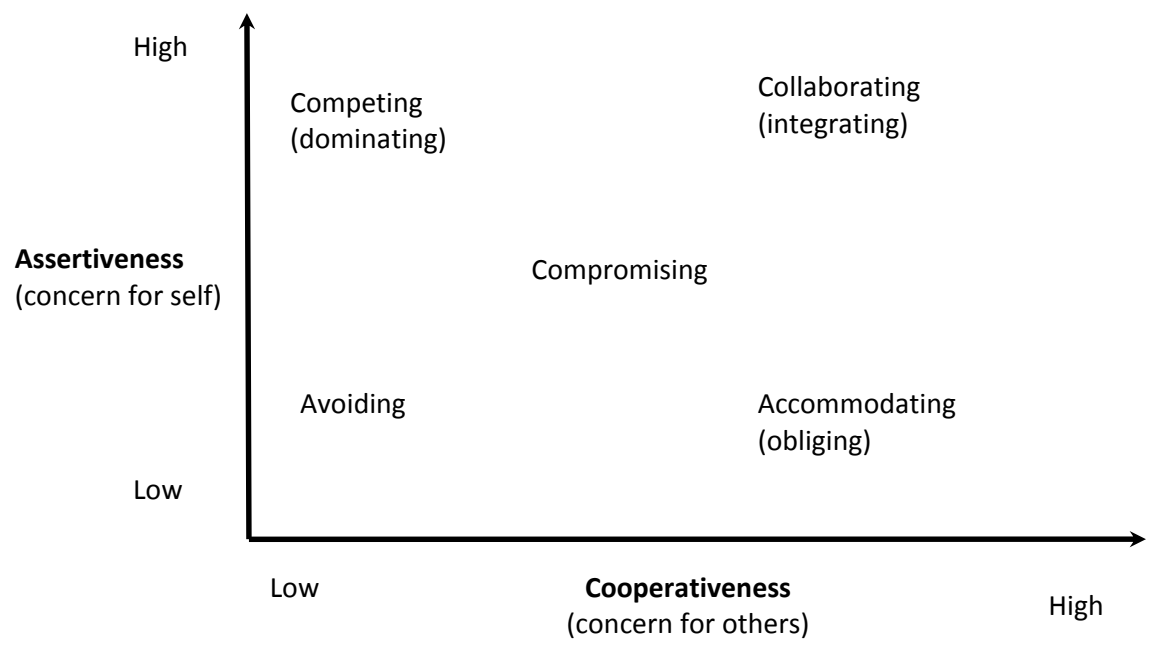

Source: Adapted from Rahim (2002) and Thomas et al. (2008)

The time and effort invested in reaching a decision on how to handle conflicts have prompted researchers to investigate the manager's individual preferences for particular handling modes (Thomas, 1976). From a psychological perspective, the conflict management mode is seen to be either contextual (i.e. a behaviour response to a situation) (Thomas, 1992; Rahim, 2002) or personality-based (i.e. relatively stable disposition depending on the type of personality and personal values) (Daly et al., 2010). Additionally, other scholars emphasise the importance of organisational aspects, such as the policies and procedures for conflict management, and line managers' training in 
handling interpersonal conflict (Teague and Roche, 2012). The influence of situational, personal and organisational aspects of line managers' decisions in handling interpersonal conflict are discussed next.

\section{Situational aspects}

Although Blake and Mutton (1964) indicate that the collaborating mode (high concern for both people and production) is most effective for managing conflicts, independent of the conflict situation, the recent re-conceptualisations of conflict management modes claim that different modes of handling interpersonal conflicts are suitable for various circumstances (Rahim, 2002). This context-based view argues that managers change their managing conflict mode depending on situational aspects of the conflict, such as the complexity and seriousness of the issue, its importance for each party, as well as the time and resources needed to solve it (Rahim, 2002). The key features of the five conflict management modes presented in Figure 1 are as follows:

1. Collaborating mode involves cooperation between the parties to reach a win-win solution that satisfies both parties. It is very similar to the integrative and problem-solving types, as all seek to find a long-term solution considering the interests of both parties (Holt and DeVore, 2005). It is considered useful when there is a complex issue, when commitment is needed from the other party for successful implementation and time is available for problem-solving. In contrast, it is considered inappropriate when an issue is simple, requires an immediate solution or the parties do not have problem-solving skills (Rahim, 2002: 219). This mode is suitable for dealing with strategic, long-term issues (Chung-Yan and Moeller, 2010).

2. Accommodating mode ignores one's own needs and is associated with attempting to play down the differences and emphasising similarities (Rahim, Magner and Shapiro, 2000). It is suitable if a party believes that he or she may be wrong or the issue is far more important for the other party and preserving the relationship is important (Rahim, 2002). There is an element of self-sacrifice in this mode, with the expectation of getting some future benefit from the other party when needed. This can be efficient in solving interpersonal relationship conflicts due to its long-term orientation (i.e. to develop trust), but not task conflicts (Chung-Yan and Moeller, 2010).

3. Competing mode has been identified with a win-lose orientation. Competing may mean standing up for one's rights and/or defending a position that the person believes to be correct (Rahim, Magner and Shapiro, 2000). It is more suitable if a speedy decision is needed, if subordinates lack the expertise to make a decision, or if it is necessary to overcome assertive subordinates; it is inappropriate if there is a complex issue, both parties are equally powerful or subordinates have high degree of competence on the issue (Rahim, 2002: 219). Canary (2003) found that competing was generally ineffective in resolving disagreements.

4. Avoiding mode is used to prevent conflict, to ignore the situation and postpone the conflict situation (Rahim, 2002). This mode could be useful only when the issue is minor and the potential dysfunctional effect of confronting the other party outweighs benefits of resolution. It is often used out of fear of confrontation due to lack of confidence in conflict management skills (Rahim, 2002). A person avoiding situations does not satisfy his/her own concerns or the concerns of the other party involved (Rahim, Magner and Shapiro, 2000). Canary (2003) found that avoidance is generally ineffective at resolving disagreements.

5. Compromising mode is associated with give-and-take and attempts to satisfy each party's concern (Thomas et al., 2008). It is suitable when the goals of the parties are mutually exclusive, while it is inappropriate if the problem is complex and requires a long-term solution based on a problem-solving approach (Rahim, 2002: 219). Rahim (2002) found that compromising is the most successful mode at resolving interpersonal conflicts.

The three conflict-handling modes that involve cooperation (accommodating, compromising and collaboration) are considered to be more effective for finding long-term solutions to conflicts, whilst the two modes characterised by low levels of cooperation are useful for dealing with short-term tactical issues (Rahim, 2002). An important shortcoming of the two-dimensional frameworks is the implicit assumption that the two parties themselves handle the conflict, while, in practice, sometimes a third party may be involved in managing an interpersonal conflict.

Similar to Daly's et al. (2010) study, our paper uses the common elements Thomas et al. (2008) and Rahim's (2002) frameworks. Nevertheless, this study gives priority to Thomas et al.'s (2008) conflict handling modes, as cooperative and assertive dimensions are more likely to be compatible with a third party intervention (i.e. a line manager handling interpersonal conflict between two subordinates), than concern for self and others (see Figure 1). More specifically, the level of cooperativeness and assertiveness of the parties involved in the conflict could be among the three parties, while the 'concern for self' dimension identified by Rahim $(1983,2002)$ is more likely to refer to only one of the conflicting parties. Both frameworks consider the conflict situation crucial for the selection of 
the conflict management mode, while omitting that some managers may not have the autonomy and the resources to use the most appropriate conflict-handling mode for a specific conflict situation. Thus, organisational and personal aspects may also affect the conflict-handling mode.

\section{Personal aspects}

In contrast to the view that the conflict management mode is adjusted to the conflict situation, some scholars argue that the mode of managing conflict is relatively stable depending on personal aspects (Daly et al., 2010). Tyler (1986) found that task-focused managers are more likely to be concerned with productivity, whereas relationshipfocused managers are more likely to focus on social harmony.

The gender of line managers may also affect their conflict management mode. Holt and DeVore (2005) performed a meta-analysis of 36 empirical studies and found out that males are more likely to endorse the use of competing mode than females, and that females are more likely to endorse the use of compromising mode than males. However, some empirical studies reveal that females are more assertive in handling conflict (Nguyen and Jang, 2012). Thomas et al.'s (2008) study of 200 males and 200 females showed that, overall, men were equally assertive as women in conflict handling. Their findings revealed that men were significantly more likely to use the competing mode, while there were no significant differences regarding the use of collaborating mode (the other highly assertive mode). Furthermore, Munduate et al.'s (1999) study found females and males have very similar patterns in conflict handling. Thus, the impact of gender differences on conflict management is unclear.

The national culture of line managers may also affect their conflict-handling mode. The results of Holt and DeVore's (2005) meta-analysis for the variables of culture reveals that individualistic cultures are more likely than collectivistic cultures to choose competing mode, while collectivistic cultures prefer the modes of avoidance, compromising and collaborating more than individualistic cultures. Their findings are substantiated by Doucet et al.'s (2009) study, which found significant differences in handling conflict between American managers and Chinese managers. In Western organisations, conflict avoidance is often seen as a counter-productive handling mode, but some studies have found that conflict avoidance is effective in collectivist societies, where harmony and saving face are highly valued (Morris et al., 1998; Doucet et al., 2009). Nevertheless, it is unclear whether the national culture of line managers is more important than the organisational culture.

Additionally, psychologists indicate that the personality of line managers affects the choice of conflict-handling modes (Jensen-Campbell and Graziano, 2005). Antonioni (1998) examined the relationship between extraversion, openness, conscientiousness, agreeableness and neuroticism and conflict-handling modes based on a survey of 351 undergraduate students and 110 managers. His findings revealed that extraversion, conscientiousness and agreeableness have a positive relationship with the collaborative conflict-handling mode for managers. Nevertheless, Moberg's (2001) investigation of 249 managers and supervisors from four organisational samples in the USA found a positive relationship between openness and agreeableness and the managers' preference for a compromising mode. With regards to the avoiding mode, Antonioni (1998) found that agreeableness had a positive relationship with it, while conscientiousness had a negative relationship with it in the managers' sample. Moberg's (2001) findings confirmed that conscientiousness is negatively related to avoiding, while he also found out that avoiding is associated positively with neuroticism and negatively with extraversion and conscientiousness. However, although personality has been shown to play a role, Antonioni (1998) indicated that personality explained generally less than 25 percent of variation in the use of specific conflict-handling modes, which implies that other factors also influence the handling of conflict by managers.

\section{Organisational aspects}

Previous studies indicate that the conflict-handling mode is affected by whether the company provides training on conflict management, the existence of conflict management procedures and the organisational norms (Hunter and Renwick, 2009; Teague and Roche, 2012). Most scholars state that the devolution of HR duties, such as conflict management to line managers, may only be successful when organisations provide adequate training and support (CIPD, 2004; Bakhare, 2010). Prior studies highlight that many organisations do not provide adequate conflict management training for line managers (CIPD, 2004). Teague and Roche's (2012) study of 360 Irish enterprises found that line managers were formally involved in conflict management, but commonly did not receive training. Cunningham and Hyman's (1999) study of four case studies showed that the line managers had insufficient preparation for conflict management. They argue that line managers often do not take their HR roles seriously and consider them 'common sense'. Their findings are supported by Brandl 
et al.'s (2009: 202) study, which found that handling conflict is considered amongst the least important HR duties of line managers.

Additionally, the organisational status of line managers may affect the conflict management mode. Brewer et al.'s (2002) study of 118 managerial and non-managerial employees in three finance-related organisations showed that upper organisational status managers were more likely to collaborate, while lower status managers opted for the use of avoiding and accommodating modes. Thomas et al.'s (2008) study of a stratified random sample of 400 working adults at six organisational levels also found a pattern of increasing assertiveness in the conflict-handling modes from the lowest to the highest organisational levels, except for the compromising mode. They found the highest use of the compromising mode at the middle levels, and the lowest at the top executive and entry levels. Thus, the expectation is that junior line managers are less likely than senior line managers to utilise assertive conflict-handling modes.

Apart from training and status, the existence of procedures for handling conflict may affect how line managers deal with conflicts. Stark (2007) states that reliance on rules generates less hostility when managing conflicts rather than exercising coercive power. Tillet (1991) also argues that it is very important to establish clear rules and procedures to ensure that line managers take into account defence mechanisms. Formal rules and procedures provide guidelines on how line managers should handle conflicts, but their implementation by line managers depends on the importance given to the handling of conflicts by their senior managers (Hunter and Renwick, 2009).

The regular appraisal of the conflict management competencies of line managers is considered essential for effective conflict management. Teague and Roche's (2012) study found that line managers generally do not receive feedback about their conflict management competence in Irish organisations. Other authors have also noted the importance of rewarding line managers for effective people management (Merchant and Wilson, 1994), in order to send a message that the organisation values behaviour that is consistent with good conflict management.

Finally, the norms and culture of an organisation may affect the conflict management mode (Teague and Roche, 2012). Tyler (1986) found out that an organisation that is focused on productivity is less likely to be concerned with fairness as the desired outcome. Additionally, most multinational organisations take great pride in their company culture and brand image, as it reflects the company's values and identifies the expectations it has from its employees. Thus, organisational norms and culture in multinational corporations are likely to affect the desired outcomes, which, in turn, may affect the conflict management mode selected by the line managers.

Summing up, the review of theoretical and empirical studies on conflict management shows disagreement on what influences the line managers' ability to handle interpersonal conflicts. Specifically, scholars who consider that the mode of managing conflict depends on the situational aspects, argue that managers frequently change their managing conflict mode (Rahim, 2002). In contrast, scholars who focused on personality, argue that managers have a relatively stable preference for a specific managing conflict mode, independent of the conflict situation (Antonioni, 1998).Finally, the third view is that the organisational context, in particular, the procedures for dealing with an interpersonal conflict, determines how the conflict is handled (Teague and Roche, 2012). Despite the vast amount of literature, no study that investigated the impact of all three sets of factors on the line managers' decisions on how to manage interpersonal conflicts was found. This paper examines whether situational, personal and/or organisational aspects affect line manager's conflict management modes, as depicted in Figure 2.

Figure 2. Key Factors Affecting Conflict-Handling Mode

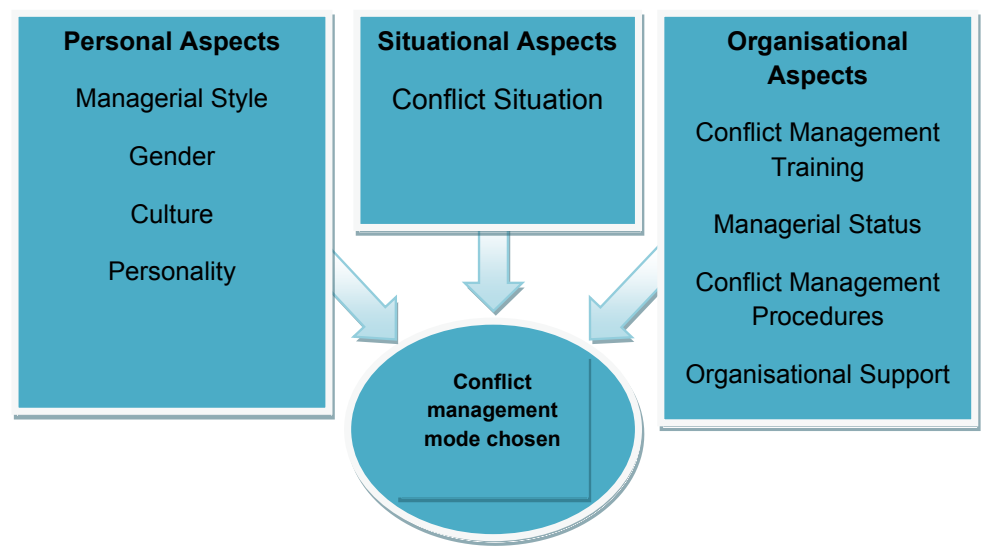




\section{Research design and organisational contexts}

As previous research indicates that line managers play a key role in managing interpersonal conflicts in nonunionised multinational corporations, two non-unionised Irish subsidiaries of multinational corporations provide the setting for this study (Björkman et al., 2011; Teague and Roche, 2012). The first subsidiary is part of an American multinational company from the hospitality industry (HotelCo), and the second one is part of a French multinational company from the beauty industry (BeautyCo). Both subsidiaries employ more than 150 employees in Ireland. The competitive strategies of the two companies are different. As HotelCo is a five-star hotel, it focuses on the quality of the services provided, while the BeautyCo is more productivity driven, as it makes products for mass consumption, such as cosmetics, haircare and skincare. Both organisations have very strong organisational cultures. The values of HotelCo are linked to the following aspects: 'do the right thing', 'go the extra step' and 'play as a team', while the values of BeautyCo are linked to respect, trust, empowerment, working together and the sense of community.

Although the two case studies operate in different industries and have different competitive strategies, their organisational aspects in relation to conflict management are very similar. Both companies provide a conflict management training, which is not compulsory for line managers. Both firms have no specific procedures for conflict management, unless when the conflict escalates and the HR is called upon to resolve the situation. Both firms have HR departments that have an open door policy and offer support whenever a line manager needs help. Finally, the line managers in both companies are not specifically appraised on their conflict management responsibility, but are appraised on their people management responsibility.

A replication methodology was used to investigate whether situational, personal and organisational factors are important in managing interpersonal conflicts in companies operating in different sectors. Three types of primary data were collected in 2011 and 2012 from a total of 21 respondents, 19 of whom were line managers and two were HR managers (11 respondents worked in HotelCo and 10 worked in BeautyCo - see Appendix 1). Firstly, all 21 respondents were asked open-ended questions about interpersonal conflict management and the impact of the organisational context on their conflict management mode. Secondly, the 19 line managers were asked to complete a personality test, based on the five-factor personality inventory, to identify their type of personality.

Finally, the 19 line managers were asked to specify the conflict management mode they use in given circumstances, to find out whether the situational factors affect the conflict management mode. Initially, the respondents were familiarised with the five conflict management modes based on Thomas's (1992) two-dimensional model of conflicthandling modes and received a hard copy of the graphical depiction of his framework. They were asked to specify the conflict-handling mode they use most often. Then, the respondents had to read three given scenarios matching Rahim's (2002) description of the avoiding mode, compromising mode and collaborating (integrative) mode. The three selected scenarios were designed to cover the entire range of conflict-handling modes in terms of the level of assertiveness and cooperativeness, as it was considered that having five scenarios would be too complex. Potential situations where interpersonal conflicts were likely to occur were identified, and the scenarios were adjusted for the context to suit the two companies. The respondents had to select only one (out of the five) conflict-handling modes that they would use in the particular conflict situation given in each scenario.

Mixed methods were used to collect primary data concerning the three sets of factors identified in the analytical framework, namely, scenarios for the situational aspects and personality tests for specific personal aspects, while the semi-structured individual interviews covered organisational aspects, as well as some personal aspects. Each interview lasted around 40 minutes. There was a thematic content analysis of the qualitative data. The sample consisted of the entire population of line managers responsible for managing employees in the two Irish subsidiaries, and a senior HR manager was interviewed in each subsidiary. A synopsis of the respondents' personal aspects (including respondents' label) and the conflict-handling modes selected by each respondent are presented in Appendix 1.

\section{Findings and analysis}

\section{Key factors affecting line managers' conflict management mode}

All respondents indicated that line managers deal regularly with interpersonal conflicts at work. Ten of the 19 line managers interviewed revealed that they handle workplace conflict on a daily basis. This section examines the 
findings concerning the effects of the situational, personal and organisational aspects of line managers' conflict management mode.

\section{Situational aspects}

The impact of the situational aspects on the conflict-handling modes is examined through given scenarios. Out of the five possible conflict-handling modes identified by Thomas (1976), three were constructed into scenarios in accordance with Rahim's (2002: 219) study of when the conflict-handling modes are appropriate to be used. The modes of conflict chosen by the 19 line managers are partially in line with Rahim's (2002) expectations (see Table 1 and Appendix 1).

Table 1. Scenario Results

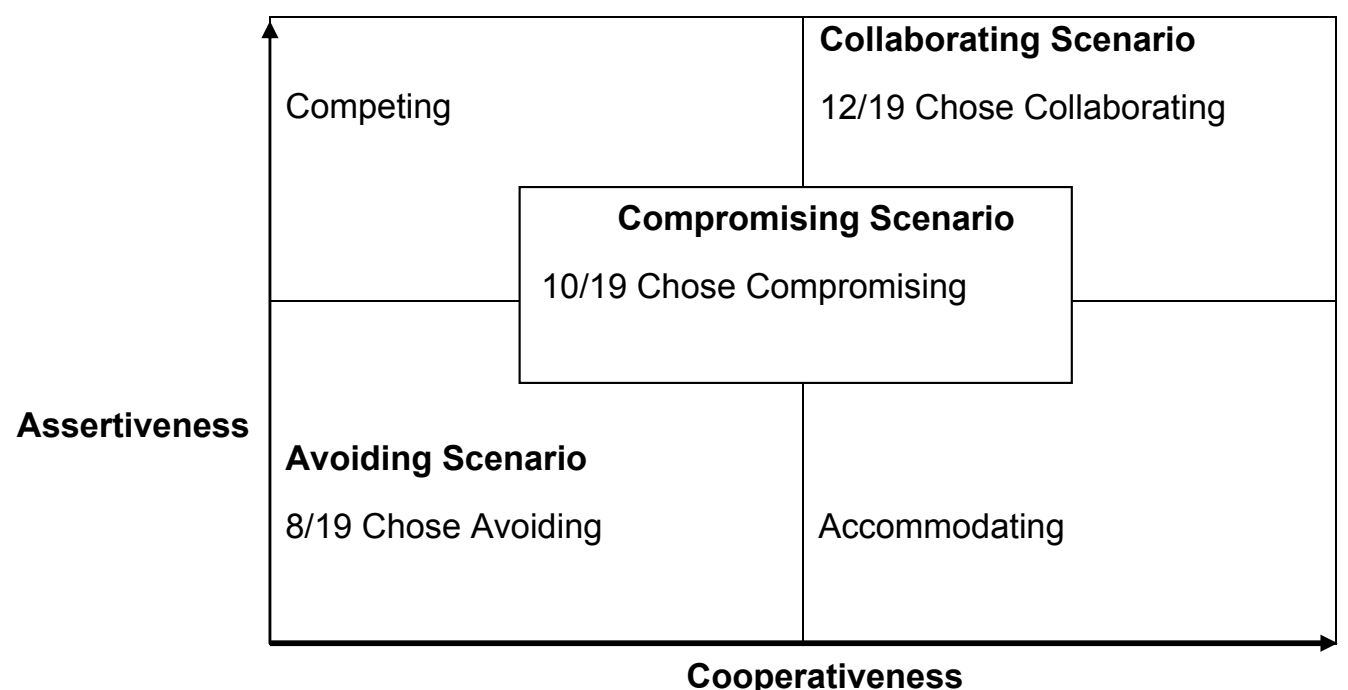

The respondents were given three scenarios matching the description of the avoiding, compromising and collaborating modes. For the collaborating scenario, 12 (out of 19) respondents selected the collaborating mode. For the compromising scenario, 10 respondents chose the compromising conflict-handling mode, while only eight selected the avoiding mode for the avoiding scenario. When the line managers were asked to choose the conflicthandling mode they use most often, virtually all of them selected the collaborating and/or compromising modes, except for one respondent who chose the avoiding mode (see Appendix 1). The findings support the view that conflict handling modes based on high levels of cooperation are more likely to be considered effective than those characterised by low levels of cooperation (Rahim, 2002; Thomas et al., 2008). Nevertheless, the chosen modes could also be a result of the respondents' tendency to self-evaluate positively.

Although, from the initial findings, it may seem that a conflict situation has little influence on the conflict-handling modes the line managers use, all the respondents chose more than one conflict-handling mode for the three given scenarios, which indicates that various conflict situations lead to different conflict-handling modes (Appendix 1). With closer examination, we can see that around half of the scenarios were answered in line with Rahim's (2002) expectations (Table 1). Also, the other chosen modes were often close to the expected one in terms of the level of cooperativeness and assertiveness (see Appendix 1). For example, out of the eight line managers that did not choose the collaborating mode for the collaborating scenario, six chose the compromise conflict-handling mode. Since respondents were asked to select only one conflict-handling mode for each scenario, these results appear to be consistent with Munduate et al.'s (1999) study, which indicated that managers do not use just one conflicthandling mode for a specific conflict situation. 


\section{Personal aspects}

The personal aspects that may affect the line manager's conflict-handling mode, are their managerial mode, gender, national culture and personality. Tyler (1986) found out that the managerial mode also impacts the conflict-handling mode. Out of the 19 line managers, seven stated that they were task-focused, and 12 that they were people-focused. The findings do not reveal major differences between the task-focused and people-focused managers in terms of their conflict-handling modes. None of the task-focused managers preferred to use the competing mode, which is in contrast to Tyler (1986) findings. This could be either due to our small sample, or the strong organisational culture in the two cases. The values of HotelCo's are to 'do the right thing' and 'play as a team', which requires compromise and collaboration, while the values of BeautyCo are respect, trust, empowerment, working together and the sense of community, which also requires collaboration and compromise.

There is a debate on whether gender differences in conflict management behaviour exist. In this study, data was collected from 11 females and eight males (line managers). Five of the 11 females expressed, that they were shy with conflict, while only one of the males did. A female line manager stated:

Honestly, I probably avoid until I taught it was serious enough for me to get involved and then collaborating. I would not be competing, but defiantly avoiding (JLM13).

In contrast, a male line manager indicated:

If a conflict arises my way of dealing with it is head on. I wouldn't keep something from me I would probably address it rather than bury my head in the sand. (SLM6)

The competing mode was selected six times in total, by four males and two females. A male line manager specified why he would use the competing mode in one of the scenarios:

I would choose competing because there is a very clear right and wrong here. (SLM16)

These findings support Rubin and Brown's (1975) study that females avoid conflict situations more than males, while also displaying some agreement that males are more competitive than females. In contrast to Holt and DeVore's (2005) study, which found out that females endorse the use of compromise more than males, this study shows that the compromise mode was used more often by males (four out of five) than females (one out of five), whilst females were more likely to use both the collaborating and compromising modes (four out of five) than men (one out of five) (Appendix 1). Their choices could have been influenced by the need to work together in both industries. The hospitality industry is fast paced and requires the departments to work together constantly, as the departments have different priorities, which would call for a lot of compromising. Similarly, the beauty industry is also constantly changing and requires the commercial, marketing and customer services to work very closely together, which would also call for a lot of compromising and collaboration. The findings are consistent with the view that gender differences in conflict management behaviour exist (Brandl et al., 2009).

Conflict avoidance is generally seen as a counterproductive handling mode in individualistic Western countries, while it is considered effective in collectivist societies (Holt and DeVore, 2005). In this study, 11 Irish line managers and eight non-Irish line managers were interviewed. The non-Irish line managers come from Italy, the UK, Brazil, Lebanon, Germany, Algeria and Slovakia (see Appendix 1). Italy, the UK and Germany have a rather individualistic culture, broadly similar to that of Ireland, whereas Brazil, Lebanon, Algeria and Slovakia are considered collectivist countries (Hofstede, 2001). Eight line managers chose the avoiding mode for the avoiding scenario, but seven of them were from individualistic countries and only one was from a collectivist country, which suggests that the line manager's national culture does not necessary influence how they handle conflict. HotelCo is an American multinational company and the USA has an extremely individualistic culture, while BeautyCo is a French multinational company and France also has an individualistic culture (Hofstede, 2001). Both case studies have a strong organisational culture and, therefore, these findings appear consistent with the notion that the organisational culture accounts for a higher variance than the national cultural (Gerhart and Fang, 2005).

Psychologists argue that personality is one of the most important aspects affecting the choice of the conflicthandling mode (Jensen-Campbell and Graziano, 2005). In this study, when the respondents were asked if they 
have any personal aspects that influence how they handled conflict, virtually all (except one) answered yes, as illustrated by the following quotes:

I suppose my personality is very expressive, so in conflict, I suppose I can be little bit maybe opinionated depending on what it is. But I also then tend to with conflict get a little bit shy and because we don't want conflict. My personality does not like conflict. (JLM1 - extroverted personality)

I am a chicken. Because I avoid these scenarios I don't like conflict. (JLM13 - open personality)

The three answers given by the line managers for the given scenarios and the conflict- handling mode they use most often enabled us to determine if there was a link between a particular type of personality and the conflict handling modes. In this study, the largest personality type was conscientious with eight (out of 19) respondents having a conscientious personality. Four (out of the eight with conscientious personality) chose the collaborating mode for the collaborating scenario and six revealed that collaborating is the conflict handling mode they utilised most often. This supports Antonioni's (1998) and Moberg's (2001) studies which reported a positive relationship between conscientiousness and the collaborating mode.

The personality types of the remaining 11 respondents were extrovert (five), agreeable (five) and open (one). The five extrovert respondents chose collaborating (nine times) and the compromising modes 15 out of a possible 20 times, supporting the numerous studies that found a positive relationship between extroversion and both collaborating and compromising modes (Antonioni, 1998; Moberg, 2001). The five respondents with an agreeable personality indicated that they prefer using the collaborating and compromising modes in equal measure, whilst they have chosen all five modes for the given scenarios. Interestingly, the respondent with an open personality was the only one who indicated that she prefers the avoidance mode, confirming Antonioni's (1998) findings. Nevertheless, this could also be due to the respondent's gender and junior management status (see JLM13 in Appendix 1). Although the findings generally support the view that personality affects the line manager's conflict handling choice, it appears that situational aspects have more influence over the line manager's conflict handling choice than personality, as none of the respondents have chosen the same conflict management mode for all three given scenarios.

\section{Organisational aspects}

Previous studies indicate that conflict management may only be successful when organisations provide line managers with adequate training and support from HR specialists (Larsen and Brewster, 2003). Although both companies have on-line conflict management training courses available, none of the respondents have taken it. The line managers were asked if they felt that training on conflict management should be provided and the response was an overwhelming yes, as illustrates by the following statements:

Yes.....Because everyone is different, everyone has different skill levels and in an organisation where you try to have fair rules and fair game that managers are trained the same way to make the same decisions, to try get the same results. (JLM10)

If you can do it that is fine you don't need it. If you don't know how to do it we will give you the training to do it. I think we should not wait to see if a manager can do it or not, just because it maybe too late because if a line manager does not know how to deal with conflict some bad decision can be taken from this and then afterwards it is too late. (SLM15)

Around a third of the line managers though that they were prepared to handle conflict due to their experience:

I think I am now, but I think that just comes with a number of years in a managerial position to be honest. (SLM7)

I think it is something that I have learnt over time. I have managed people for twenty years and I have learnt most through making mistakes and getting it right the next time round, through specific training. (JLM11) 
A lack of experience and training in managing people was identified as a problem for the newly appointed managers:

When you move into managerial roles you actually don't do any training on managing people, which is probably the most challenging part of your job and so that is where a lot of the challenges arise because you are literally learning on the job. (SLM7)

Line managers stated that conflict management training should be made mandatory for all of them. This corresponds with the findings of Hunter and Renwick (2009: 405), who indicated that line managers believed that their greatest development needs are in the area of discipline and grievance handling. Cunnigham and Hyman's (1999) suggestion that the line managers do not take their new HR roles seriously, is not supported by this study. Some respondents were of an opinion, that it is difficult to train line managers on how to handle conflict, but they did not oppose training. These line managers felt that competence in the area is gained from experience.

There were 11 junior line managers (JLM) and 8 senior line managers (SLM) in our sample (Appendix 1). The results of the given scenarios show that only 3 SLM (out of the 8) chose the avoidance mode, while 7 (out of the 11) JLM chose the avoiding mode, which provides support for Brewer et al.'s (2002) findings concerning greater use of the avoiding mode by lower status managers.

In both companies, senior managers revealed that lower levels managers and supervisors were often not capable of managing conflicts successfully:

....it is a lack of maybe experience or something so yeah I see different levels of capabilities with dealing with conflict, for sure yeah. (SLM5)

I think when you start out in a managerial role your natural instinct is to shy away from it or to avoid it. (SLM7)

They [junior line managers] need assistance. My assistance and HR assistance. I don't think they are ready for conflict. (SLM18)

The two HR managers confirmed that there is a difference in how line managers handle conflict based to their status:

I think [head of department] would have more experience than the [supervisors] and that really is what the difference is.....Supervisors don't always deal with conflict because they don't always know that it is conflict, so supervisors can brush it under the carpet and let it go.....because they are kind of scared or intimidated by the people involved or intimidated by the situation and really that is lack of experience. (HR1 - HotelCo)

I do think so..... I had a few where effectively it was like I am sorry but I am the manager, so he or she should agree to what I say and there is no point in having conflict because this is the way we are going. (HR2 BeautyCo)

These findings substantiate the studies of Brewer et al. (2002) and Thomas et al. (2008) by indicating that the line managers' status affects their conflict-handling mode. In addition, the findings emphasise the importance of management experience in dealing with interpersonal conflicts.

Furthermore, the conflict management procedures, which govern how the line managers are supposed to handle conflict within an organisation, may affect the conflict handling modes (Teague and Roche, 2012). The interviews revealed that there are no formal conflict management procedures for interpersonal conflicts in the two companies. In both cases managing conflicts was covered under the umbrella of grievance and disciplinary procedures, which is similar to the findings of Teague and Roche (2012). The line manager generally takes the role of a mediator and would go to the HR department for advice if needs be, as indicated by the following statements:

Clear procedures, I don't think we have that to be honest.... there is no such thing as process to deal with. (SLM6 - HotelCo)

I don't think anything specific. First round is me trying to resolve it. Try and try again and then it is an escalation process to my line manager and HR. (JLM19 - BeautyCo) 
The line managers in the two large subsidiaries of multinational corporations are given the power to handle a conflict how they see fit, which is similar to the findings of Hunter and Renwick (2009) from a small non-profit organisation.

Although the line managers lack conflict management procedures and training, all respondents felt that they had enough support from the HR department and their managers. The organisational support in the two cases appears to be more substantial than the average in Ireland. Teague and Roche's (2012) study found out that line managers rarely receive support in managing workplace conflicts. The reason for this could be the organisations' strong culture, valuing cooperation and teamwork. Nevertheless, the line managers mentioned that they learn from, and follow the example of, their own manager. This could have negative results, as their line managers do not receive training and could be managing conflicts unsuccessfully.

Finally, the line managers have a performance management process three times a year in HotelCo, and twice a year in BeautyCo, but the large majority of the respondents were not appraised on their conflict handling. Only four respondents considered that they were appraised indirectly, as people's development is part of their appraisal. This study supports Teague and Roche's (2012) findings, which indicate that line managers do not receive a recurrent assessment of their competence in relation to their conflict management. Also, it suggests that line managers are unlikely to improve their handling of conflicts if they do not get any feedback on how they handle them. Some authors have stated the importance of rewarding line managers for effective people management, to send a message that the organisation values behaviours consistent with good conflict management (Merchent and Wilson, 1994). Since most line managers do not receive direct assessment for their conflict management responsibility, the companies may send a message that conflict management is not important.

\section{Discussion and conclusion}

This study investigated the main factors affecting line managers' handling of interpersonal conflicts. While previous studies examined either the effects of the conflict situation (Rahim, 2002; Thomas et al. 2008) and the personal aspects (Antonioni, 1998; Moberg, 2001), or the role of organisational aspects of managing interpersonal conflicts (Teague and Roche, 2012), this paper combined the psychological and managerial approaches of conflict management to provide a more comprehensive analysis of the aspects that influence how line managers handle interpersonal conflicts. Although this is an exploratory study, it makes two main contributions to a better understanding of the interpersonal conflict management.

Firstly, it develops an analytical framework that identifies and explains the three main sets of factors (situational, personal and organisational) that are most likely to affect the handling of interpersonal conflicts by line managers (see Figure 2). This framework was applied in the case of two non-unionised companies operating in different sectors. The findings revealed that all three sets of factors influence how conflict is handled in both companies but our limited empirical evidence does not allow us to specify whether each of those three sets of factors has a significant influence on managing conflicts by line managers. Nevertheless, the paper suggests that combining psychological and managerial approaches to managing conflicts provides a fuller understanding of handling interpersonal conflicts. It provides an analytical framework that could be used for further research on managing interpersonal conflicts at work.

Secondly, the paper provides original findings on how line managers handle interpersonal conflicts, contributing to a better understanding of the under-researched area of the actual HR role of line managers (Hunter and Renwick, 2009). This study is consistent with the previous studies indicating that line managers are usually responsible for managing interpersonal conflicts at work, while they get limited (if any) conflict management training and feedback on how they handle conflict (Hunter and Renwick, 2009; Teague and Roche, 2012). In line with the previous studies (Rahim, 2002; Thomas et al., 2008), the data indicates that line managers are more likely to use cooperative modes of conflict management (collaboration and compromising) than those based on high assertiveness, independent of the conflict situation. It suggests that the main personal aspects that influence line managers are gender and personality. The management style and national culture do not seem to influence the chosen conflict-handling mode, which might be due to the strong organisational culture of the two case studies, or the methodological limitations.

The organisational aspects that influenced the line managers are the support they receive from their line managers and the HR department, the organisational status, the lack of conflict management training and the lack of adequate appraisal for their conflict management competency, which is consistent with the previous studies (Hunter and Renwick, 2009; Teague and Roche, 2012). In addition to Teague and Roche's (2012) study, which 
focused solely on the organisational aspects of conflict management, this paper suggests that the conflict situation and the personal aspects also affect how the line managers handle interpersonal conflicts. Moreover, as all of the respondents have chosen more than one mode of handling conflict for the three given scenarios (Appendix 1), the findings support the view that line managers' conflict management mode is more likely to be contingent on the conflict situation than on the personal aspects. Thus, it supports the view that conflict management is adjusted by line managers to the conflict situation and the organisational aspects, rather than being relatively stable depending on their personal aspects.

\section{Limitations and further research}

Despite using mixed methods to gather primary data, this is an exploratory case study research based primarily on qualitative data, causing issues of generalisability of the findings. Caution must be exercised in interpreting our empirical findings, particularly the quantitative data concerning the links between personal aspects and conflict management modes, as the sample was very small and we used conflict scenarios. Additionally, the self-reported conflict management modes could be biased towards positive conflict management modes, such as the collaborating and compromising modes. These methodological limitations make it very difficult to explain findings that are in contrast to the previous studies. Nevertheless, the research design allows for identifying whether situational, personal and organisational aspects of line managers affect the mode of managing interpersonal conflicts. Although further research is needed to examine whether or not situational, personal and organisational aspects have significant and comparable influence on handling interpersonal conflicts by line managers in different organisational contexts, this study contributes to the under-researched area of the role of line managers in dealing with negative HR aspects.

\section{References}

Antonioni, D. (1998). 'Relationship between the big five personality factors and conflict management styles'. International Journal of Conflict Management, 9(4), 336-355.

Bakhare. R. (2010) 'The manager and conflict management'. Journal of India Management, 7(4), 41-57.

Blake, R.R. and Mouton, J.S. (1976). The managerial grid, Michigan: Gulf Pub Book Division.

Brewer, N., Mitchell, P. and Weber, N. (2002). 'Gender role, organizational status, and conflict management styles'. International Journal of Conflict Management, 13(1), 78-94.

Björkman, I., Ehrnrooth, M., Smale, A. and John , S. (2011). 'The determinants of line management internalisation of HRM practices in MNC subsidiaries'. The International Journal of Human Resource Management, 22(8), 1654-1671

Brandl, J., Madsen, M.T., and Madsen, H. (2009). 'The perceived importance of HR duties to Danish line managers'. Human Resource Management Journal, 19(2), 194-210.

Canary, D.J. (2003). 'Managing interpersonal conflict: a model of events related to strategic Choices' in: J.O. Greene and B.R. Burleson (eds) Handbook of Communication and Social Interaction Skills, Mahwah: Lawrence Erlbaum Associates, 515-549.

CIPD (2004) Managing Conflict at Work: A survey of the UK and Ireland, available from: <http://www.cipd. co.uk/subjects/empreltns/general/_mngcnflt04. $\mathrm{htm}$ ? IsSrchRes=1 [Accessed on 7th October 2010].

Chung-Yan, G.A. and Moeller, C. (2010). 'The psychosocial costs of conflict management styles'. International Journal of Conflict Management, 21(4), 382-399.

Cunningham, I. and Hyman, J. (1999). 'Devolving HR responsibilities to the line-beginning of the end or a new beginning for personnel?'. Personnel Review, 17(8), 5-20.

Daly, T.M., Lee, J.A., Soutar, G.N. and Rasmi, S. (2010). 'Conflict-handling style measurement: a bestworst scaling application'. International Journal of Conflict Management, 21(3), 281-308

Dana, D. (2001). Conflict resolution: mediation tools for everyday work life, USA: McGraw-Hill Professional.

Darling, J. R. and Walker, W. E. (2001). 'Effective conflict management: use of the behavioural style model'. Leadership and Organisational Development Journal, 22(5), 230-242.

De Dreu, C.K.W. and Weingart, L. (2003). 'Task versus relationship conflict, team performance, and team member satisfaction: a meta-analysis'. Journal of Applied Psychology, 88(4), 741-749.

Doucet, O., Poitras, J., Chênevert, D. (2009). 'The impacts of leadership on workplace conflicts'. International Journal of Conflict Management, 20(4), 340-354. 
Gerhart, B. and Fang, M. (2005). 'National culture and human resource management: Assumptions and evidence'. International Journal of Human Resource Management, 16(6), 971-986.

Hofstede, G.H. (2001). Culture's consequences: comparing values, behaviours, institutions, and organizations across nations, second edition. Beverly Hills: Sage Publications.

Holt, J.L. and DeVore, J.C. (2005). 'Culture, gender, organisational role and stress of conflict resolution: a meta-analysis'. International Journal of Intercultural Relations, 29(2), 165-196.

Hunter, W. and Renwick, D. (2009). 'Involving British line managers in HRM in a small non-profit work organisation'. Employee Relations, 31(4), 398-411.

IBEC. (2008). The Essential Guide to Alternative Dispute Resolution. Dublin: IBEC.

Jensen-Campbell, L.A. and Graziano, W.G. (2005). 'Methodologies for studying personality processes in interpersonal conflict'. International Negotiation, 10(1), 165-182.

Kilmann, R.H. and Thomas, K.W. (1975). 'Interpersonal conflict-handling behavior as a reflection of Jungian personality dimensions'. Psychological Reports, 37, 971-980.

Kleinman, G., Palmon, D., Lee, P. (2003). 'The effects of personal and group level factors on the outcomes of simulated auditor and client teams'. Group Decision and Negotiation, 12(1), 57-84.

Larsen, H.H. and Brewster, C. (2003). 'Line management responsibility of HRM: What is happening in Europe?'. Employee Relations, 25(3), 228-244.

Merchant, G. and Wilson, D. (1994), 'Devolving HR in the Civil Service', Personnel Management, January: 38-41.

Moberg, P.J. (2001). 'Linking conflict strategy to the fivefactor model: theoretical and empirical foundations'. International Journal of Conflict Management, 12(1), 47-68.

Morris, M.W., Williams, K.Y., Leung, K., Larrick, R., Mendoza, M.T., Bhatnagar, D., Li, J., Kondo, M., Luo, J.L. and Hu. J.C. (1998). 'Conflict management style: accounting for cross-national differences'. Journal of International Business Studies, 29(4), 729-748.
Munduate, L., Ganaza, J., Peiro M.J. and Euwema, M. (1999). 'Patterns of styles in conflict management and effectiveness'. International Journal of Conflict Management, 10(1), 5-24.

Nguyen, H.D., Yang, J. (2012). 'Chinese employees' interpersonal conflict management strategies'. International Journal of Conflict Management, 23(4), 382-412.

Rahim, M.A. (2002) 'Toward a theory of managing organizational conflict'. International Journal of Conflict Management, 13(3), 206-235.

Rahim, M.A., Magner, R.N., and Shapiro, D.L. (2000). 'Do justice perceptions influence styles of handling conflict with supervisors?: What Justice perceptions, precisely?'. International Journal of Conflict Management, 11(1), 9-31.

Rubin, J.Z. and Brown, B.R. (1975). The social psychology of bargaining and negotiation, New York: Academic Press.

Stark, R. (2007). Sociology. New Jersey: Jossey-Bass.

Teague, P. and Roche, W.K. (2012). 'Line managers and the management of workplace conflict: evidence from Ireland'. Human Resource Management Journal, 22, 235-251.

Thomas, K.W. (1976). 'Conflict and conflict management' in: M.D. Dunnette (ed) Handbook of Industrial and Organizational Psychology, Chicago: Rand-McNally, 889-935.

Thomas, K.W. (1992). 'Conflict and conflict management: reflections and updates'. Journal of Organizational Behavior, 13(3), 265-274.

Tillet, G. (1991). Resolving conflict: a practical approach, Victoria: Sydney University Press.

Thomas, K.W., Thomas, G.F. and Schaubhut, N. (2008). 'Conflict styles of men and women at six organization levels'. International Journal of Conflict Management, 19(2), 148-166.

Tyler, T. (1986). 'When does procedural justice matter in organizational settings?' in: R.J. Lewicki, B.H. Sheppard M.H. Bazerman (eds) Research on negotiation in organizations, Greenwich: JAI, 7-23.

Wall, J.A. and Callister, R.R. (1995). 'Conflict and its management'. Journal of Management, 21(3), 515-558. 


\section{Appendix 1: Conflict Handling Modes, Personal and Situational Aspects}

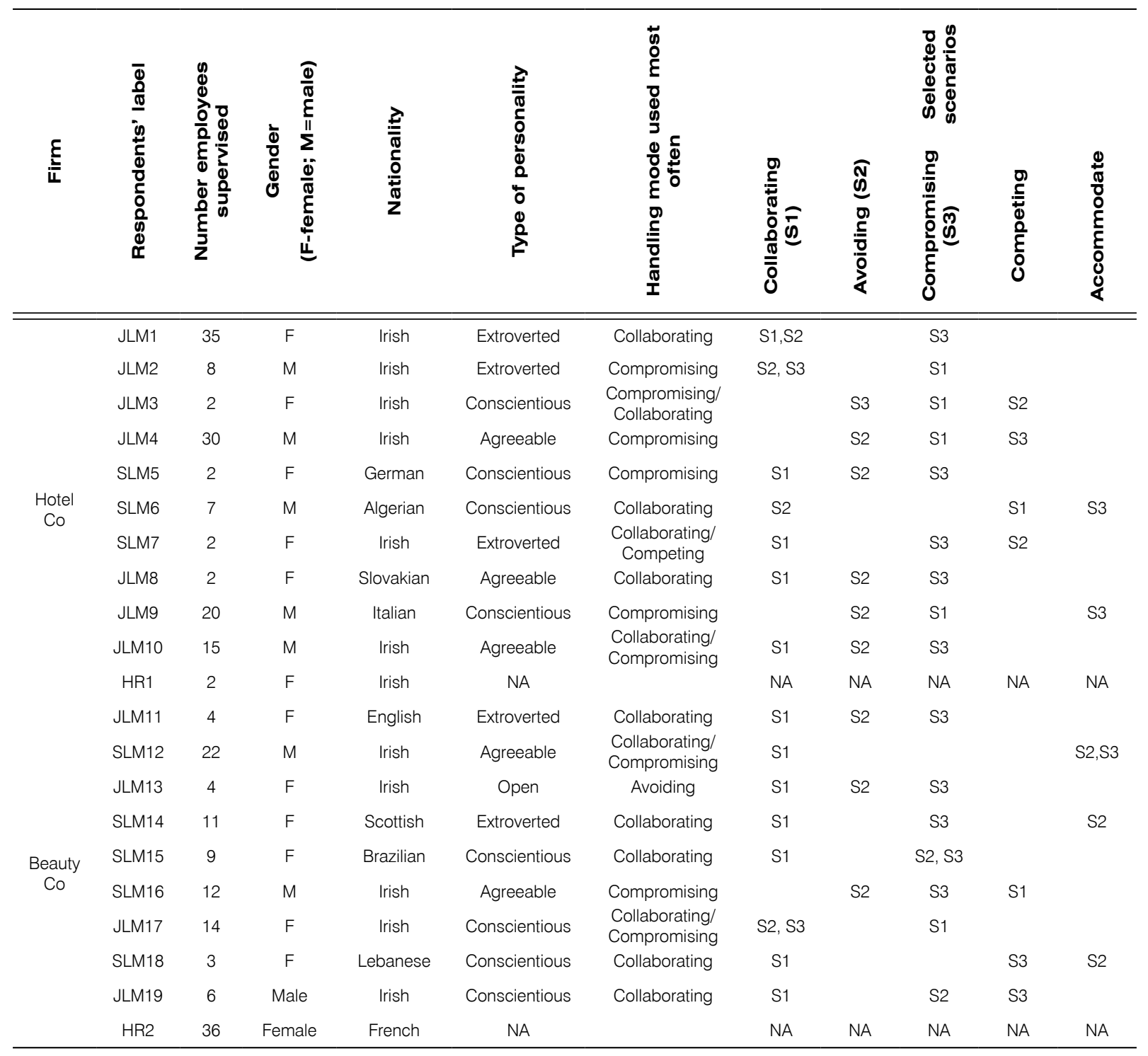

Note: JLM = Junior Line Manager; SLM = Senior Line Manager; HR = Human Resource Manager 